\title{
Sobrevivência e perfil de resistência a antimicrobianos de Salmonella sp. isoladas em um sistema de tratamento de dejetos de suínos ${ }^{1}$
}

\author{
Survival and resistance patterns of Salmonella sp. isolated in a pig slurry treatment plant
}

\author{
Verônica Schmidt ${ }^{2}$ Marisa Ribeiro de Itapema Cardoso ${ }^{2}$
}

RESUMO

No presente estudo, foi avaliada a sobrevivência de Salmonella sp., presente em dejetos suínos, durante tratamento em um sistema de separação física e lagoas de estabilização ligadas em série. Nas amostras de Salmonella sp. isoladas foi determinado o perfil de resistência pelo método de difusão em ágar, usando 14 antimicrobianos. Das 20 coletas realizadas, foi possivel isolar Salmonella sp. em 13 coletas no ponto correspondente ao início do sistema de tratamento e em apenas uma no ponto final do mesmo. Amostras de Salmonella sp. isoladas (161/163) pertenciam ao sorotipo Typhimurium e demonstraram resistência contra sulfonamida (100\%), tetraciclina $(99,4 \%)$, estreptomicina $(90,1 \%)$, sulfal trimetoprima $(84,5 \%)$, ácido nalidixico $(77,6 \%)$, ampicilina $(76,4 \%)$, cloranfenicol $(29,2 \%)$, cefaclor $(25,5 \%)$, tobramicina $(13,7 \%)$, gentamicina $(6,2 \%)$, amoxacilina/ácido clavulânico (5\%), neomicina (5\%) e amicacina (3,7\%). A maioria $(94,5 \%)$ das amostras isoladas foram resistente a 4 ou mais antimicrobianos e apresentaram grande variabilidade nos perfis de resistência. O nível de resistência e a variabilidade dos perfis mantiveram-se em nivel semelhante ao longo do sistema.

Palavras-chave: Salmonella Typhimurium; resistência a antimicrobianos, suínos, lagoas de estabilização.

\section{ABSTRACT}

The survival of Salmonella sp. in pig slurry submitted to treatment in successive stabilization ponds on a pig-breeding farm was investigated. Furthermore, the isolated Salmonella strains were tested for their resistance against 14 antibiotics, using the agar diffusion method. Of a total of 20 samples taken from different points in the stabilization ponds system, 13 were positive for Salmonella sp. in the beginning and only one at the end of the system. Most of the isolated Salmonella strains (161/163) belonged to sorovar Typhimurium.
These strains were resistant to sulfonamide (100\%), tetracycline (9.4\%), sulfamethoxazole/trimethoprin (84.5\%), ampicillin (76.4\%), cloramphenicol (29.2\%), streptomycin (90.1\%), nalidixic acid (77.6\%), tobramycin (13.7\%), neomycin (5\%), amikacin (3.7\%), cefaclor (25.5\%), gentamicin (6.2\%) and amoxacilin/ clavulanic acid (5\%). Most Salmonella Typhimurium strains (94.5\%) were resistant to 4 or more antibiotics. The multi-resistance level and the pattern variability of these strains were similar in the beginning and at the end of the stabilization ponds system.

Key words: Salmonella Typhimurium; antibiotic-resistance, swine, stabilization ponds.

\section{INTRODUÇÃO}

O aumento da importância dos produtos de origem suína como fonte de contaminação por Salmonella sp. em humanos tem resultado na preocupação em avaliar e controlar a presença desta bactéria em rebanhos de todo o mundo (BLAHA, 2001). Ao lado disto, o uso crescente de antimicrobianos na suinocultura industrial tem sido acompanhado pela emergência de linhagens resistentes em diversos microrganismos, inclusive aqueles patogênicos (FEDORKA-CRAY et al., 1999).

Bactérias resistentes a antimicrobianos podem ser encontradas no ambiente contaminado com efluente industrial, humano ou animal, local onde sofrem pressão de seleção (LINTON, 1988). As plantas de tratamento de águas residuais podem ser consideradas o recipiente principal dos microorganismos entéricos carreadores de genes de

${ }^{1}$ Parte da Tese do primeiro autor, apresentada ao Programa de Pós-graduação em Ciências Veterinárias, Universidade Federal do Rio Grande do Sul (UFRGS).

${ }^{2}$ Médico Veterinário, Professor do Departamento de Medicina Veterinária Preventiva, Faculdade de Veterinária, UFRGS. Av. Bento Gonçalves, 9090, 91540-000, Porto Alegre-RS, E-mail: veronica.schmidt@ufrgs.br 
resistência (ANDERSEN, 1993). Entretanto a importância destes sistemas de tratamento na seleção ou eliminação de cepas multi-resistentes permanece controversa. No caso de $\boldsymbol{E}$. coli, tem sido proposto que a passagem por lagoas de estabilização selecionaria as linhagens mais resistentes e propiciaria a troca de determinantes de resistência a antimicrobianos entre grupos de enterobactérias (HASSANI et al., 1992; MEZRIOU \& BALEUX, 1994). No que se refere à passagem de dejetos contaminados com Salmonella sp. através de sistemas aeróbios ou anaeróbios de tratamento, parece haver a remoção das bactérias presentes (JURIS et al., 1995; 1996). Estudos quanto ao perfil de resistência das linhagens de Salmonella sp. ao longo de sistemas de tratamento não foram encontrados.

O objetivo do presente estudo foi determinar a presença de Salmonella sp. durante o tratamento de dejetos suínos em lagoas de estabilização, bem como comparar o perfil de resistência a antimicrobianos das amostras bacterianas isoladas em diferentes pontos da planta de tratamento.

\section{MATERIAL E MÉTODOS}

O sistema de tratamento estudado localiza-se no sul do Brasil, recebendo dejetos de cerca de 4.000 matrizes e 30.000 suínos em crescimento e terminação. Os dejetos liqüefeitos são levados até tanques de armazenamento localizados imediatamente antes da planta de tratamento. Após a etapa de separação física em peneiras, a fração sólida é direcionada para a lagoa de lodo e a fração líquida, para um tanque de sedimentação seguido por sete lagoas em série (duas anaeróbias, uma facultativa, uma com aeração mecânica e três aeróbias). Foram realizadas 20 coletas quinzenais em sete pontos ao longo do sistema de tratamento: após os tanques de armazenamento (P1), após o tanque de sedimentação (P3), após a lagoa de lodo (PA), após a segunda lagoa anaeróbia (P9), após a lagoa facultativa (P10), após a lagoa com aeração mecânica (P11) e após a terceira lagoa aeróbia (P14) (Figura 1). As amostras coletadas em cada ponto foram refrigeradas e enviadas para serem processadas no Setor de Medicina Veterinária Preventiva da UFRGS.

O isolamento de Salmonella sp. foi feito como descrito por MICHAEL (2000). As colônias confirmadas como Salmonella sp. foram mantidas congeladas $\left(-20^{\circ} \mathrm{C}\right)$ em caldo Infusão Cérebro e Coração acrescido de $20 \%$ de glicerol, até serem remetidas para sorotipagem no Instituto Oswaldo Cruz.
De todos os pontos nos quais houve isolamento de Salmonella sp., no mínimo duas colônias confirmadas foram testadas quanto à resistência a antimicrobianos. Para tanto, foi utilizado o método de difusão em ágar (BARRY \& THORNSBERRY, 1985), sendo testados discos (Cecon) impregnados com os seguintes antimicrobianos: ácido nalidíxico (na; $30 \mu \mathrm{g}$ ), amicacina $(\mathrm{a} ; 30 \mu \mathrm{g})$, amoxacilina/ácido clavulânico

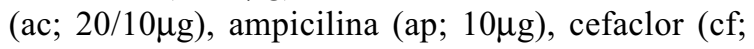
$30 \mu \mathrm{g})$, ciprofloxacina $(\mathrm{cp} ; 5 \mu \mathrm{g})$, cloranfenicol (c; $30 \mu \mathrm{g})$, estreptomicina $(\mathrm{e} ; 10 \mu \mathrm{g})$, gentamicina $(\mathrm{g}$; $10 \mu \mathrm{g})$, neomicina ( $\mathrm{n} ; 30 \mu \mathrm{g})$, sulfonamida (su; 300 $\mu \mathrm{g})$, sulfa/trimetoprima $(\mathrm{s} ; 5 \mu \mathrm{g})$; tetraciclina $(\mathrm{t} ; 30 \mu \mathrm{g}) \mathrm{e}$ tobramicina $(\mathrm{tb} ; 10 \mu \mathrm{g})$.

Para o cálculo do índice de multiresistência (MAR) das amostras de Salmonella sp., os resultados obtidos nos sete pontos amostrados ao longo do sistema foram divididos em três grupos: S1 (PA, P1 e P3), S2 (P9) e S3 (P10, P11 e P14). O índice MAR foi calculado separadamente para cada grupo através da fórmula $\mathrm{a} /(\mathrm{bxc})$, onde $a$ é o escore de resistência agregada de todas as amostras de Salmonella sp. pertencentes ao grupo; $b$ é o número de antimicrobianos testados no estudo e $c$ é o número de amostras de Salmonella sp. no grupo testado (KRUMPERMAN, 1983; KASPAR \& BURGES, 1990).

As diferenças significativas entre resistência antimicrobiana nos diferentes pontos foram determinadas pelo teste $\mathrm{t}(\mathrm{P}<0,05)$. Para a construção do dendograma, os dados foram convertidos em código binário e a semelhança entre as amostras foi medida através do coeficiente de Dice entre grupos (Average linkage). Os dados foram avaliados estatisticamente utilizando o programa SPSS 8.0 (CÁCERES, 1995).

\section{RESULTADOS E DISCUSSÃO}

Foi possível confirmar a presença de Salmonella sp. em 13/20 coletas realizadas no P1 (tanque de armazenamento), indicando que a bactéria estava presente na granja durante o período do estudo. A constatação da presença de Salmonella sp. em sistemas de produção de suínos tem ocorrido mundialmente, principalmente em função de um monitoramento mais rigoroso desencadeado por programas de controle de microrganismos potencialmente patogênicos na cadeia alimentar (BLAHA, 2001). A possibilidade de eliminação de elevado número de salmonelas nas fezes de animais portadores assintomáticos acarreta, entre outros problemas, na preocupação com o destino dos dejetos 


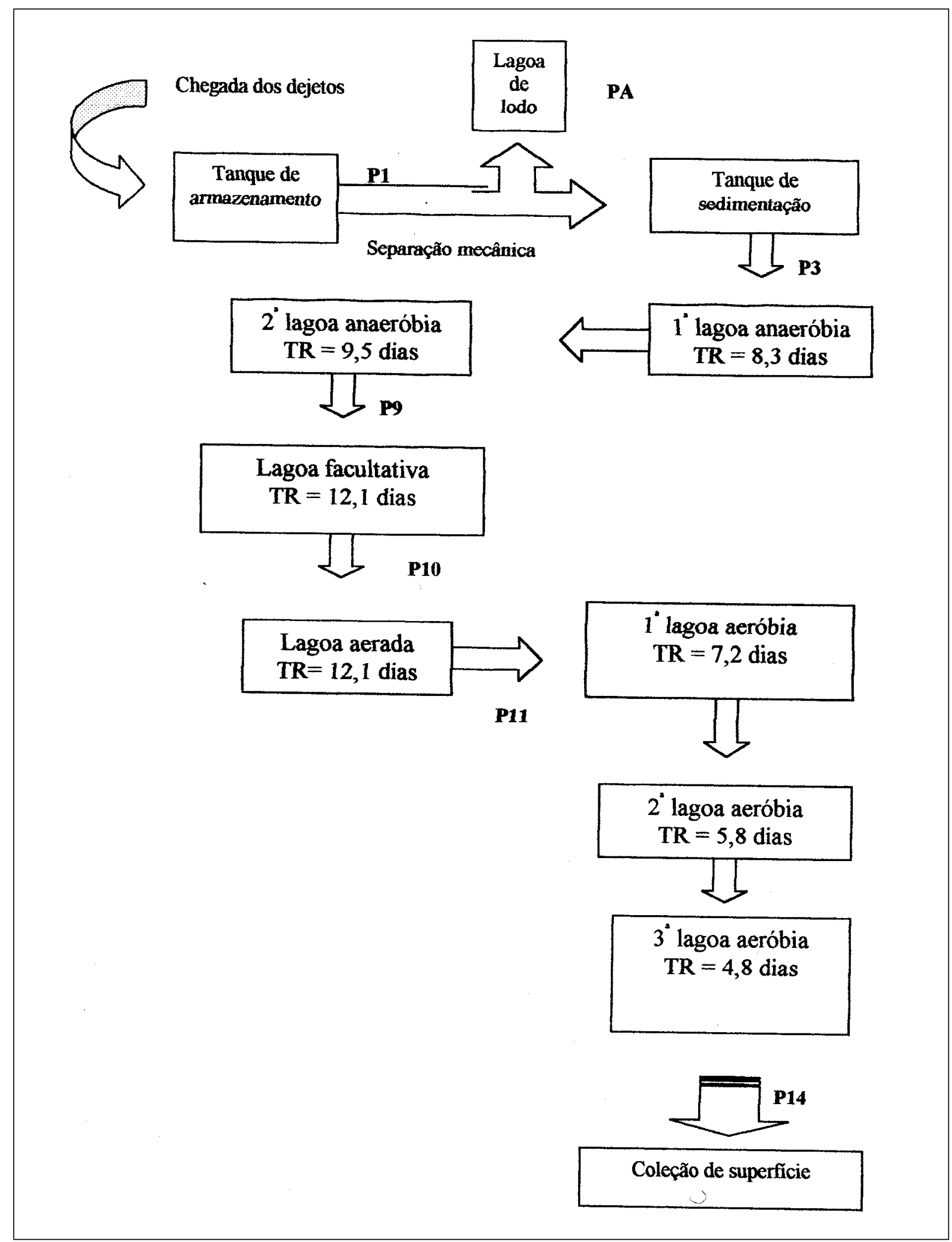

Figura 1 - Representação esquemática do fluxo hídrico de um sistema de tratamento de dejetos de uma granja de ciclo completo na produção de suínos, no Sul do Brasil. Onde TR é o tempo de retenção (em dias).

Ciência Rural, v. 33, n. 5, set-out, 2003. 
gerados no sistema de produção, o que pode ser um fator importante na cadeia de transmissão da bactéria para animais e humanos. (HEINONEN-TANSKI, 1998; BLAHA, 2001).

O tratamento de dejetos, além de ter importância nos sistemas intensivos como atenuador do impacto que a deposição de matéria-orgânica e nutrientes causam no ambiente, também tem demonstrado ser uma ferramenta para diminuir o risco sanitário que os mesmos podem representar (STRAUCH, 1991). Esta observação pode ser confirmada no presente estudo, o qual demonstrou um decréscimo gradual no isolamento de Salmonella sp. ao longo das lagoas de estabilização (Figura 2), encontrando-se apenas 1/20 amostras positivas no final do sistema (P14). Avaliando o índice de isolamento ao longo das diferentes lagoas que compõem o sistema, observa-se que houve um decréscimo acentuado após as lagoas anaeróbias (P9) e facultativa (P10). Os mecanismos que determinaram a redução da população de Salmonella sp. nestas lagoas podem estar relacionados a mudanças nas condições ambientais como o pH, a concentração de oxigênio e de nutrientes disponíveis (STRAUCH, 1991).

A diminuição da população de Salmonella sp. em dejetos suínos foi anteriormente relatada, tanto em sistemas aeróbios como anaeróbios (JURIS et al., 1995; 1996; HAINONEN-TANSKI, 1998) em índices que variaram entre $90-99 \%$. No presente estudo, houve também uma redução na ordem de $93 \%$ no número de ocasiões em que houve isolamento de Salmonella sp. no final do sistema em comparação como o início do mesmo. Estes dados permitem afirmar que o sistema foi eficiente na redução da população desta bactéria quando presente nos dejetos.

Já quando analisamos as etapas (P1, P3 e PA), anteriores ao tratamento biológico nas lagoas de estabilização, observa-se que os índices de isolamento de Salmonella sp. foram semelhantes. Este fato indica que o armazenamento e separação física da fração sólida e líquida dos dejetos não influenciou na viabilidade da bactéria. Também não parece ter havido uma variação na presença de Salmonella sp. nas frações sólida e líquida separadas. A tendência de um menor índice de isolamento, observada no lodo separado no tanque de sedimentação (P3) e armazenado em lagoa adjacente ao sistema (PA), pode ter sido resultante da grande dificuldade de homogeneização deste tipo de material no momento da coleta das amostras.

Desta forma, a separação mecânica não demonstrou ser eficiente na eliminação de Salmonella sp., indicando que tanto a fração líquida como a sólida devem ser tratadas antes de serem depositadas no meio ambiente. Principalmente o lodo gerado pela separação física, se aplicado diretamente sobre o solo como adubo em hortas e pastagens, pode vir a oferecer risco para humanos e animais.

De um total de 163 colônias submetidas à caracterização antigênica, 161 foram identificadas

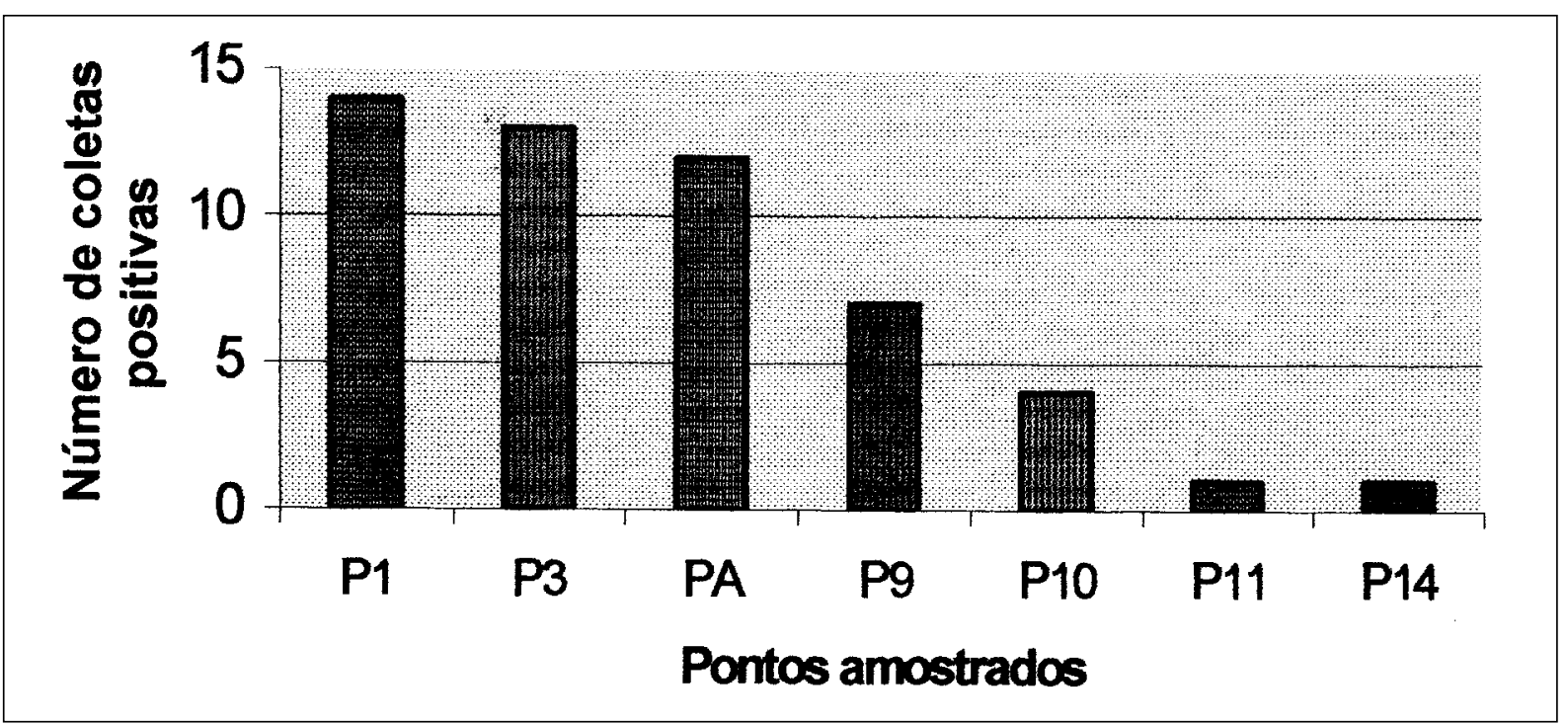

Figura 2 - Número de coletas com isolamento de Salmonella sp. dentre 20 realizadas em sete pontos de um sistema de lagoas interligadas para o tratamento de dejetos de suínos, onde: P1= após o tanque de armazenamento, P3= após o tanque de sedimentação, PA= após a lagoa de lodo, P9= após a segunda lagoa anaeróbia, P10= após a a lagoa facultativa, P11= após a lagoa com aeração mecânica e P14= após após a terceira lagoa aeróbia. 
como Salmonella Typhimurium. É surpreendente que, ao longo de 10 meses de realização de coletas, não tenha havido variação no perfil de sorovares presentes nos dejetos, uma vez que a infecção por salmonela nos suínos caracteriza-se pela grande variabilidade de sorovares encontrados nos animais e no ambiente (BLAHA, 2001). A exemplo disto, MICHAEL et al. (2002), no Rio Grande do Sul, identificou 15 sorovares diferentes presentes numa granja onde estava ocorrendo um surto de infecção por Salmonella sp. Uma vez que a metodologia empregada no isolamento já foi capaz de detectar diferentes sorovares a partir de fezes de suínos (BESSA et al., 2001) e as colônias foram escolhidas aleatoriamente para identificação, resta supor que a propriedade possa ter uma fonte comum de contaminação, ou que esteja havendo algum tipo de seleção que acarrete a predominância do sorovar Typhimurium sobre os demais.

Outra preocupação crescente tem sido o desenvolvimento de resistência em bactérias, principalmente aquelas com risco de disseminação entre animais e humanos, como é o caso da Salmonella Typhimurium (WITTE, 2000). Exceto à ciprofloxacina, contra a qual todas as amostras foram sensíveis, os índices de resistência apresentados foram variáveis: sulfonamida $(100 \%)$, tetraciclina $(99,4 \%)$, estreptomicina $(90,1 \%)$, sulfonamida/trimetoprima $(84,5 \%)$, ácido nalidíxico $(77,6 \%)$, ampicilina $(76,4 \%)$, cloranfenicol $(29,2 \%)$, cefaclor $(25,5 \%)$, tobramicina $(13,7 \%)$, gentamicina $(6,2 \%)$ e amoxacilina/ácido clavulânico (5\%), neomicina (5\%), amicacina $(3,7 \%)$. O número de marcadores de resistência concomitantes apresentado pelas amostras variou entre dois ( 2 amostras) e onze antimicrobianos (2 amostras), sendo a maioria das amostras $(30,4 \%)$ resistentes a seis antimicrobianos.

Se a utilização de antimicrobianos na ração tem demonstrado um efeito favorável na produtividade de sistemas intensivos de produção de suínos (STAHLY et al., 1980), o uso de antimicrobianos na produção animal, por outro lado, tem sido apontado como possível causa de emergência de organismos multi-resistentes (MATHEW et al., 1999). Três fatores são apontados como responsáveis pela emergência de resistência: a associação de genes de resistência com elementos transponíveis (transposons); o contato estreito entre bactérias no ambiente; e a pressão de seleção exercida pelo uso de antimicrobianos (SCHWARZ \& CHASLUS-DANCLA, 2001).

Nos sistemas de tratamento de dejetos, a proximidade entre as populações microbianas e a presença de resíduos de antimicrobianos podem ocorrer, tornando-os um local apropriado para a seleção de linhagens resistentes e transferência dos determinantes de resistência, conforme já foi demonstrado (ANDERSEN, 1993; MEZRIOUI \& BALEUX, 1994). No período de estudo, haviam sido utilizados, como promotores de crescimento ou terapeuticamente, lincomicina, amoxacilina, sulfadiazina, trimetoprima, gentamicina, norfloxacina, tilosina e oxitetraciclina. Comparando os níveis de resistência encontrados entre os antimicrobianos testados e o grupo utilizado, é possível observar que apenas a gentamicina apresentou níveis baixos de resistência na população. Dentre os quatro antimicrobianos com maior nível de resistência (sulfonamida, tetraciclina, estreptomicina e sulfa/ trimetoprima), três foram utilizados como aditivos no período. Apesar de estudos mais aprofundados a respeito da associação entre a utilização de antimicrobianos e a dinâmica do aparecimento de resistências ainda serem necessários, a maior resistência à tetraciclina em $\boldsymbol{S}$. enterica já foi correlacionada, por ISAACSON et al. (2001), com o tempo de uso deste antimicrobiano em uma propriedade. Ao lado disto, parece haver uma variação no aparecimento de linhagens resistentes em sistemas de ciclo completo, como é o caso da propriedade estudada. MATTHEW et al. (2000) observaram que, em propriedades com uso intenso de antimicrobianos, a idade dos animais era um fator importante no nível de resistência de $\boldsymbol{E}$. coli presentes no trato gastrintestinal. De acordo com este estudo, o aumento de linhagens resistentes ocorria em animais após o desmame, sendo que as razões para este fato seriam o maior uso de antimicrobianos nesta idade, bem como a colonização com novas linhagens bacterianas que ocorreriam nesta fase.

Dividindo-se as amostras isoladas em todos os pontos em três grupos: $\mathrm{S} 1(\mathrm{n}=138), \mathrm{S} 2(\mathrm{n}=15)$ e $\mathrm{S} 3$ $(\mathrm{n}=11)$, não houve diferença significativa no índice de multi-resistência a antimicrobianos (MAR) calculado para os diferentes grupos $(\mathrm{S} 1=0,43 ; \mathrm{S} 2=0,46$ e $\mathrm{S} 3=0,41)$. A percentagem de amostras resistentes aos diferentes antimicrobianos sofreu variação ao longo do sistema, tendo havido um aumento considerável nas amostras resistentes ao cloranfenicol no final do sistema (Figura 3).

Embora a redução de índices de resistência em microorganismos entéricos já tenha sido relatado em sistemas de tratamento de dejetos suínos e urbanos (AVIGNON \& LAFONT, 1985), outros estudos afirmam haver uma tendência ao aumento do percentual de resistência a antimicrobianos, principalmente durante o tratamento aeróbico de esgotos (MOROZZI et al., 1988). Ainda, 


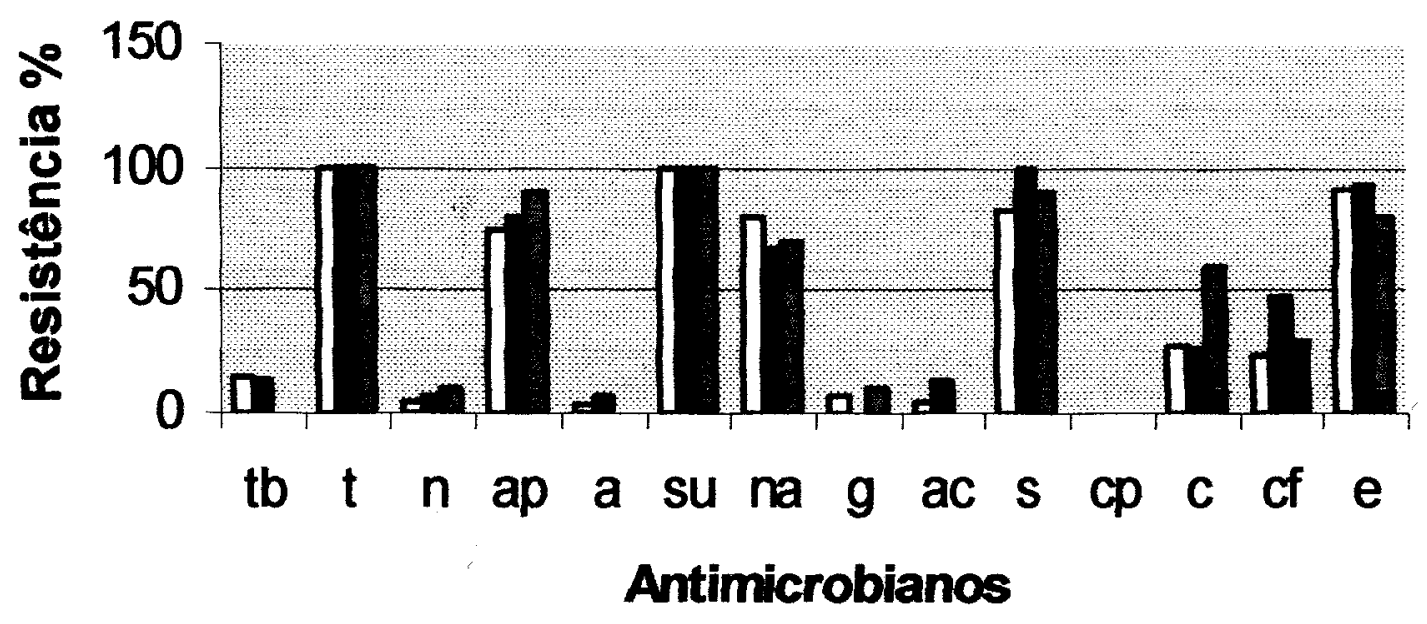

$\square S 1 \square S 2 \mathrm{DS} 3$

Figura 3 - Resistência antimicrobiana (\%) de 161 amostras de Salmonella Typhimurim isoladas em diferentes pontos de um sistema de tratamento de dejetos suínos. S1= após tratamento físico (pontos PA, P1 E P3); S2= após lagoa anaeróbia (P9); S3= após lagoas facultativas (P10, P11 e P14); $\mathrm{tb}=$ tobramicina, $\mathrm{t}=$ tetracilina, $\mathrm{na}=$ ácido nalidíxico, $\mathrm{a}=$ amicacina, $\mathrm{c}=\mathrm{cloranfenicol}, \mathrm{e}=$ estreptomicina, $\mathrm{g}=$ gentamicina, $\mathrm{ap}=$ ampicilina, $\mathrm{ac}=$ amoxacilina, $\mathrm{cp}=$ ciprofloxacina, $\mathrm{s}=$ cotrimoxazol, $\mathrm{su}=$ sulfonamida, $\mathrm{cf}=$ cefaclor, $\mathrm{n}=$ neomicina.

KRUPERMAN (1983) observou uma aumento no índice MAR em amostras de $\boldsymbol{E}$.coli isoladas de dejetos humanos, em comparação com amostras isoladas de fezes individuais. O autor apontou como possível causa a troca de determinantes de resistência que ocorreria entre bactérias durante a permanência no ambiente.

Da mesma forma, KRUMPERMAN (1983) definiu, arbitrariamente, o índice MAR de 0,2 para classificar as amostras de $\boldsymbol{E}$. coli como potenciais reservatórios de determinantes de resistência. Segundo o índice proposto, a média do índice MAR das amostras de Salmonella Typhimurium encontrada em todos os grupos estaria dentro da faixa de alto risco. Resultado semelhante foi também encontrado por KRUMPERMAN (1983), para amostras de $\boldsymbol{E}$. coli isoladas de suínos.

Apesar de todas as amostras pertencerem ao sorotipo Typhimurium, foi possível identificar 57 perfis de resistência diferentes. $\mathrm{O}$ perfil mais freqüente (ap-c-e-na-su-t) foi identificado em 38 (23,6\%) das amostras, porém $28,6 \%$ dos perfis encontrados foram representados por apenas uma. Esta elevada variabilidade nos perfis pode ser constatada na análise do coeficiente de similaridade medida pelo coeficiente de Dice (Figura 4). Tenover et al. (1995), em estudos genotípicos, sugerem que amostras que apresentem coeficinete maior que $70 \%$ sejam considerados similares. No presente estudo, observou-se amostras com perfis de resistência com coeficiente menor que $70 \%$ formaram 20 grupamentos distintos (clusters) sendo que destes, nove foram representados por apenas uma amostra, caracterizando a alta variabilidade nos perfis encontrados no sistema estudado.

A alta variabilidade de perfis de resistência esteve presente já no início do sistema (P1). Da mesma forma, analisando as três amostras isoladas na única coleta positiva no final do sistema (P14), observou-se a ocorrência de perfis diferentes para cada uma das amostras, sendo que o coeficiente de similaridade, estre estas, variou entre 70 e $85 \%$. A partir disto, tudo indica que as amostras já chegaram ao sistema de tratamento com alta variabilidade de perfis de resistência e que não houve uma seleção de qualquer um dos perfis ao longo do tratamento.

\section{CONCLUSÕES}

O processo biológico, no sistema de lagoas em série para o tratamento de dejetos de suínos, foi capaz de diminuir a população de Salmonella sp. presente, sendo a etapa anaeróbia a que apresentou 


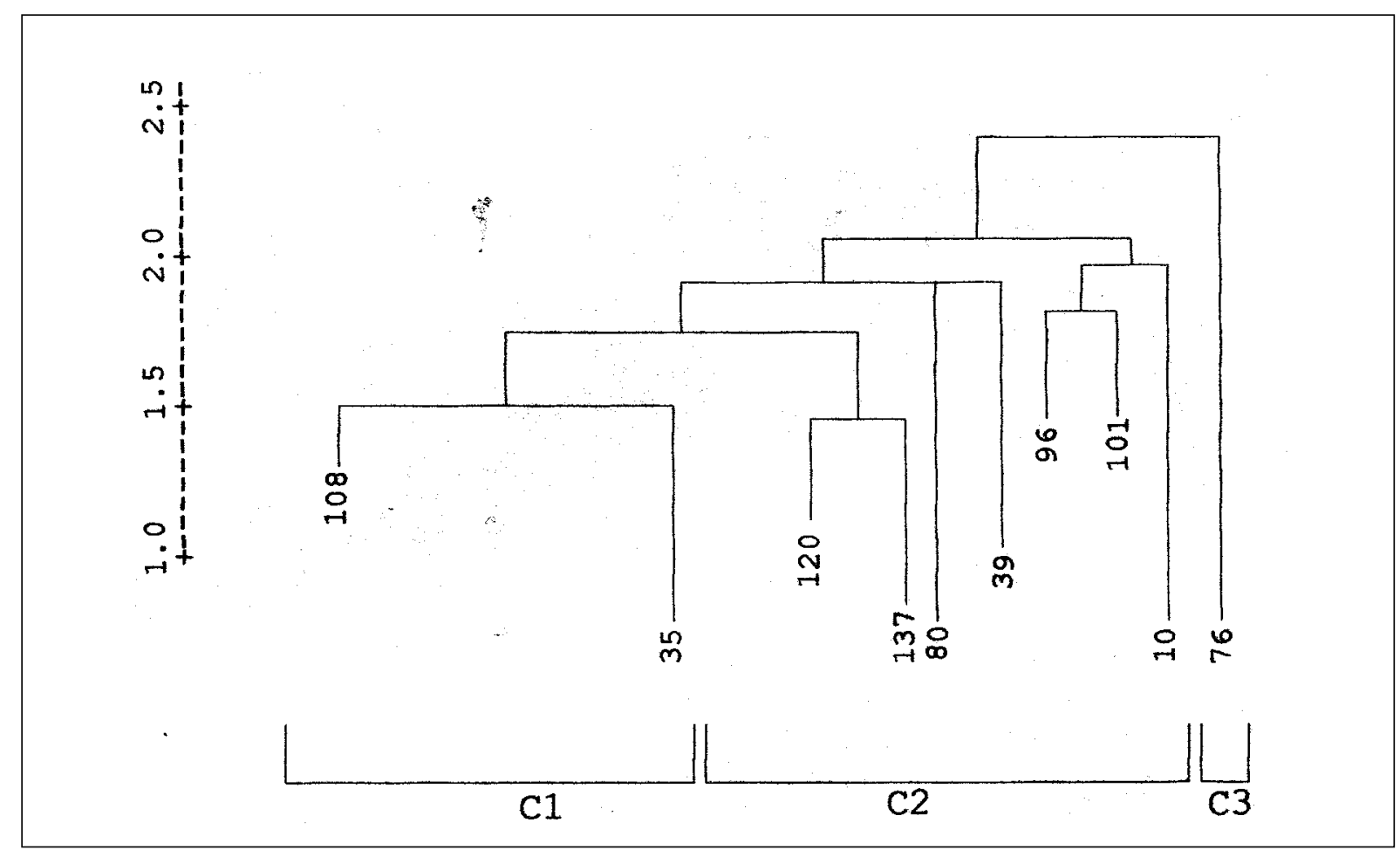

Figura 4 - Dendrograma do perfil de resistência antimicrobiana de 161 amostras de Salmonella Typhimurium determinadas através da medida Euclidiana. Os clusters foram definidos na distância Euclidiana de 2,0. Números no dendograma re' presentam padrões de resistência antimicrobiana e não o númeroda amostra

maior decréscimo no índice de isolamento. Nas amostras de Salmonella Typhimurium isoladas não se verificou modificação da multi-resistência a antimicrobrobianos ao longo do sistema de tratamento, bem como não foi possível observar a seleção de um perfil de resistência.

\section{REFERÊNCIAS BIBLIOGRÁFICAS}

ANDERSEN, S.R. Effects of waste water treatment on the species composition and antibotic resistance of coliform bacteria. Curr Microbiol, New York, v.26, p.97-103, 1993.

AVIGNON, M.; LAFONT, J.P. [Antibiotic-resistant coliforms in a purification station on a pig-breeding farm]. Ann Rech Vet, v.16, n.3, p.245-253, 1985.

BARRY, A.L.; THORNSBERRY, C. Susceptibility test: diffusion test procedures. In: LENNETE, E.H. et al. Manual of clinical microbiology. 4.ed. Washington: ASM, 1985. Cap.102, p.978987.

BESSA, M.; COSTA, M.; CARDOSO, M. Prevalence of Salmonella sp. in slaughtered pigs in Rio Grande do Sul, Brazil. In: INTERNATIONAL SYMPOSIUM ON THE EPIDEMIOLOGY AND CONTROL OF SALMONELLA IN PORK, 2001, Leipzig. Anais... Leipzig : ADDIX, 2001. p.189-191.
BLAHA, T. Pre-harvest food safety as integral part of quality assurance systems in the pork chain from stable to table. In: INTERNATIONAL SYMPOSIUM ON THE EPIDEMIOLOGY AND CONTROL OF SALMONELLA IN PORK, 2001, Leipzig. Anais... Leipzig : ADDIX, 2001. p.7-13.

CÁCERES, RA. Estadística multivariante y no paramétrica com SPSS. Madrid : Diäz de Santos, 1995. 389p.

FEDORKA-CRAY, P.J. et al. National antimicrobial resistence monitoring system: results for swine. In: INTERNATIONAL SYMPOSIUM ON THE EPIDEMIOLOGY AND CONTROL OF SALMONELLA IN PORK, 1999, Washington. Anais... Washington : ADDIX,1999. p.248-249.

HASSANI, L.; IMZILN, B.; GAUTHIER, M.J. Antibiotic-resistant Escherichia coli from wastewater before and after treatment in stabilization ponds in the arid region of Marakech, Moroco. Let Appl Microbiol, London, v.15, p.228-231, 1992.

HEINONEN-TANSKI, H. et al. Salmonella in animal slurry can be destroyed by aeration at low temperature. J Appl Microbiol, Oxford, v.85, n.2, p.277-281, 1998.

ISAACSON, R.E. et al. Antibiotic resistance patterns and genotypes of Salmonellae within swine production systems and the relationship to on farm use of antibiotics. In: INTERNATIONAL SYMPOSIUM ON THE EPIDEMIOLOGY AND CONTROL OF SALMONELLA IN PORK, 2001, Leipzig. Anais... Leipzig : ADDIX, 2001. p.396-398. 
JURIS, P.; PLACHY, P.; LAUKOVA, A. Devitalization of bacterial and parasitic germs in sewage sludge during aerobic digestion under laboratory conditions. Vet Med, Praga, v.40, n.5, p.157$162,1995$.

JURIS, P. et al. Survival of model bacterial strains and helminth eggs in the course of mesophilic anaerobic digestion of pig slurry. Vet Med, Praga, v.41, n.5, p.149-153, 1996.

KASPAR, C.W.; BURGES, J.L. Antibiotic resistance Indexing of Escherichia coli to identify sources of fecal contamination in water. Can J Microbiol, Ottawa, v.36, p.891-894, 1990.

KRUMPERMAN, P.H. Multiple antibiotic resistance indexing of Echerichia coli to identify hihg-risk sources of fecal contamination of foods. Appl Environ Microbiol, Washingron, v.46, n.1, p.165-170, 1983.

LINTON, A.H. Plasmids in the environment. Schriftenr Ver Wasser Boden Lufthyg, v.78, p.197-224, 1988).

MATHEW, A.G. et al. Multiple antibiotic resistance patterns of Escherichia coli isolates from swine farms. Appl Environ Microbiol, Washingron, v.65, n.6, p.2770-2772, 1999.

MEZRIOUX, N.; BALEUX, B. Resistance patterns of E.coli strains isolated from domestic sewage before and after treatment in both aerobic lagoon and activated sludge. Wat Res, New York, v.28, n.11, p.2399-2406, 1994.
MICHAEL, G.B. et al. Sorotipos de Salmonella isolados em uma propriedade e suínos de terminação no sul do Brasil. Ciência Rural, Santa Maria, v.32, n.3, p.525-527, 2002.

MOROZZI, G. et al. The effect of anaerobic and aerobic wastewater treatment on faecal coliforms and antibiotic-resistant faecal coliforms. Zentralbl Bakteriol Mikrobiol Hyg [B], Stuttgart, v.185, n.4-5, p.340-349, 1988.

SCHWARZ, S.; CHARLU-DANCLA, E. Use of antimicrobials in veterinary medicine and mechanisms of resistance. Vet Res, Cambridge, v.32, n. $3 / 4$, p.201-226, 2001.

STAHLY, T.S.; CROMWELL, G.L.; MONEGUE, H.J. Effects of dietary inclusion of copper and(or) antibiotics on the performance of weanling pigs. J Anim Sci, Champaing, v.51, p.1347-1351, 1980 .

STRAUCH, D. Survival of pathogenic micro-organisms and parasites in excreta, manure and sewage sludge. Vet Sci Tech, v.10, n.3, p.813-846, 1991.

TENOVER, F.C. et al. Interpreting chromosomal DNA restriction patterns produced by pulsed-field gel eletrophoresis: criteria for bacterial typing. J Clin Microbiol, v.33, p.2233-2239, 1995.

WITTE, W. Ecological impact of antibiotic use in animals on different complex microflora: environment. Int J Antim Ag, Amsterdam, v.14, p.321-325, 2000. 